\title{
Image Slice Thickness
}

National Cancer Institute

\section{Source}

National Cancer Institute. Image Slice Thickness. NCI Thesaurus. Code C106534.

The dimension between two surfaces of an imaging plane. 